\title{
Intelligent design of smart home in the family retirement model
}

\author{
Jiao $\mathrm{Li}^{1, \mathrm{a}}$ \\ ${ }^{1}$ Wuhan university of technology, Wuhan huaxia institute of technology, hubei, China. \\ a13600496@qq.com
}

Keywords: family retirement; smart home; intelligent design.

Abstract: Ageing of population is a key problem which will be faced by our country. According to the characteristics of intelligent home and analysis of the needs of the elderly, this paper put forward the principles and requirements of intelligent home design in the model of family retirement model, and adopted the modern science and technology in intelligent home products in order to provide a comfortable, safe and happy living environment for the elderly.

\section{Introduction}

Since the implementation of the family planning policy in China in 1970s, the population of our country has been declining year by year. With the deepening of China's reform and open, the social economy has been developed continuously, the people's living standard have been increased continuously, the living conditions and medical level have been improved continuously. and the people's life spans have been prolonged continuously. China has formally became the aging society. With the development of society, the development of transport, the employment opportunities and industries provided for people have been expanded continuously, and the first generation of only children are also facing the problem to support four elderly in a family. Distance problems, economic problems in the employment in reality cause it tiring for them to take care of themselves, which also cause that nobody take care of the elderly living hardly in the 'empty nest'. The emergence and development of smart home made the elderly self-care and social care combined, greatly improved the living standard and living comfort of the elderly, provided rich educational, cultural and entertainment resources for the elderly.

\section{Features of smart home and analysis of the needs of the elderly}

Intelligent home is a product under the influence of the Internet and the Internet of things, with the family housing as the basis, by integrating the information and facilities related to the home life, build efficient, convenient, comfortable and safe home living management system, so as to realize the residence requirement which combines automatic control and manual control ${ }^{[1]}$.

Compared with ordinary home, smart home doesn't only have relevant functions of ordinary home, but also has functions such as information interaction, network communication, operation automation and so on. The purpose is to adapt to people's life needs through objects, so that people can control the corresponding home products through voice, gesture, Internet and other methods, enabling people to place their home products in accordance with their ideological work in advance, so that they can serve people automatically.

The design of intelligent home system under the family retirement mode should take full account of the actual needs of the elderly and meet the related characteristics of the living environment of the elderly. Through the analysis of the needs of the elderly in China at the present stage, we believe that the following aspects are mainly included.

(1) Basic living requirements. For the reasons like age, physical condition and mental condition, the children being not around, it is difficult to normally meet the basic living security of the family retirement elderly, their basic necessities of life are limited, it is urgent to solve their daily life.

(2) The demand for safety of life. The need for safety in life is one of our basic needs and is especially important for the elderly. Due to various reasons, elderly people at home are in need of timely help 
when they are sick or in urgent situations. At the same time, the elderly, especially the elderly who live alone are also vulnerable to some law-breakers, and whose personal safety are threatened.

(3) The demand for information exchange. The old people in the home are also part of the society. They also need to know the affairs of the state, understand the people and things around them, and get relevant information. They are alone so they are eager to communicate with their family, neighbors, or relatives and friends in some ways ${ }^{[2]}$.

(4) The demand for recreational activities. The elderly have had a sense of loss after leaving their jobs for many years. Therefore, it is an urgent problem for the elderly to have a rich entertainment life, cultivate new pleasures of life and be integrated into it. With more free time and a variety of forms of outdoor activities, many kinds of entertainment will take up most of their time. Especially for the inconvenient elderly, their thirst for the sunshine, grass and trees is unexpected for our young people.

(5) The demands of realizing self value. The elderly are commonly known as "old children", who do not give up to the age, do not admit that they become old, who have very strong self - esteem. Many times, they hope to make full use of their expertise and spare time to contribute to the society and others, win the respect of others, which is another form of realizing their own life value.

\section{Principles and requirements of smart home design under the home retirement mode}

In the design process of intelligent home under the home retirement mode, the most basic requirement is to take full account of the real conditions and needs of the elderly, and try to meet the safety, convenience and efficiency from the functional perspective. Therefore, the principles and requirements of intelligent home design for the elderly mainly include the following aspects:

(1) The principle of high security. The elderly have high safety requirements for all kinds of home appliances because of their inconvenient action and lagging reaction. It mainly includes: control and use of smart home appliances, line safety and leakage protection, all kinds of barrier free furniture and equipment placement, fault tolerance of various kinds of products during operation, safe and stable operation under complex conditions.

(2) The principle of practicality and ease of operation. Practicality and ease of operation are the problems that must be taken into account during the design product process. Especially for the elderly group, start from the practicality, when fully satisfy the needs of the elderly in daily entertainment, we should consider the daily recreation and safety of the elderly. In terms of ease of operation, the elderly do not pay much attention to whether products are 'top, great, luxury' because of their thoughts and memory. They are more concerned about the practicality of intelligent products, whose functions are simple, easy to operate and easy to use.

(3) The principle of high integration and private data security. Smart home should take full account of the characteristics of the elderly, and integrate their needs as far as possible, rather than using one system after another, one button after another to achieve their requirements. Private data is crucial to the security of the elderly, including personal safety and property safety. Once the relevant data information of the elderly is obtained by the law- breaker, it is possible to seriously threaten the security and privacy of the elderly. For the elderly, their own prevention ability is low, once the risk occurs, the consequences are often very serious.

(4) The principle of economical efficiency and timeliness. Because the smart home products involve a wide range of technology, and very stringent requirements, the price of its products may be far beyond the capacity of the general family. Therefore, the economy of the smart home products should be taken full account in the process of design and manufacture, methods like large-scale, mass production, standardized production, modularization, installation, purchase and flexible control can be taken to reduce the cost of purchase and use. The timeliness principle of intelligent home design is mainly reflected in the emergency treatment and management related to family health care. It mainly includes the collection and feedback of the physical signs of the elderly, the rehabilitation treatment and reminders for all kinds of diseases of the elderly, and the information transmission of the elderly under 
urgent circumstances, all of which require timely acquisition and feedback of the data by smart home products.

\section{Analysis of the application of modern science and technology in home retirement smart home products}

Smart home is characterized by its high technology content, complete functions, convenience and flexibility. We can provide services for the daily life of the elderly by setting up the system of products, so as to make up for the shortage of failing to take care of the elderly timely because the children are far away from home. The application scope of smart home products can be gradually expanded from the following aspects to every aspect of people's daily life.

(1) The design of smart home product style. In the process of design, the characteristics of the elderly should be fully reflected, conform to the principle of ergonomics, and the process of wearing should be simple. Especially for medical related intelligent products, the layout of each monitoring point, sensor arrangement and data reading need high integration of electronics, materials, textile, communication, information and other related technologies.

(2) The application of wireless network in the remote control of smart home. By installing APP products, we can achieve remote control of smart home at home, enabling people to control all kinds of home appliances even they are outside. At the same time, children and health care workers can also pay attention to the living environment of the elderly and the operating status of the related electrical appliances in the home by the same way ${ }^{[3]}$.

(3) Foreknowledge of danger monitoring. Modern families can carry out real-time monitoring of the environment security of the whole family through various sensors. For gas leakage, illegal entry, fire and through the analysis of the elderly body data, identify unstable factors and other real-time feedback, inform relevant departments and their children in time to avoid various pinches.

(4) Human-computer interaction intelligentization. Through technologies like voice recognition, fingerprint recognition, face recognition and motion recognition, we can achieve "communication" between home and the elderly, change passivity into the initiative to achieve interactive intelligent control, have achieved the timely response of home to the elderly. In recent years, with the development of artificial intelligence and sensor technology, it has been widely applied to living environment cleaning, indoor temperature and humidity regulation, and various life reminders.

(5) Rich and diverse family entertainment functions. In order to avoid the loneliness of the elderly, improve their lifestyle, we should adopt modern media technology in intelligent application system, fully meet the entertainment and communication needs of the elderly, including home video, online video calls, entertainment with relevant people through the network ${ }^{[4]}$.

\section{Conclusion}

With the massive increase of the elderly population in China, various forms of elder supported mode and old-age products have been continuously introduced. In the family retirement model, how to meet the daily needs of the elderly and how to ensure the life of the elderly are the key problems we are facing. Intelligent Home, as a product of the development of modern science and technology, through the redesign of the elderly residential and home products, with networking technology and human-computer interaction technology as the carrier, it meets the demands of the elderly daily home care to the utmost, so that they can really be supported and have fun when they are old.

\section{References}

[1] Han Yu, Hou Yiyi. High-rise residential barrier free facilities construction in the home care mode [J]. Industry and Technology Forum.(2012). 
[2] Lu Weiliang. Intelligent residential area and smart home [M]. Beijing: Higher Education Publishing House (2009).

[3] Chen Hong, Zhang Donghui. Residential barrier free design and characteristics of disabled group [D]. Zhengzhou University( 2011).

[4] Yu Yifan. Design of the living environment of Singapore [J]. City Planning (2012). 